\title{
Which Users Should Be the Focus of Mobile Personal Health Records? Analysis of User Characteristics Influencing Usage of a Tethered Mobile Personal Health Record
}

Guna Lee, $R N, P h D_{1}{ }^{1}$ Joong Yeol Park, MD, PhD, ${ }^{1,2}$ Soo-Yong Shin, PhD, ${ }^{1,3}$ Jong Su Hwang, BS, Hyeon Jeong Ryu, MS, Jae Ho Lee, MD, PhD, ${ }^{3,5,6}$ and David W. Bates, MD, MS

${ }^{1}$ Ubiquitous Health Center, ${ }^{3}$ Department of Biomedical Informatics, and ${ }^{4}$ Medical Information Office, Asan Medical Center, Seoul, Korea.

Departments of ${ }^{2}$ Endocrinology/Metabolism and ${ }^{6}$ Emergency Medicine, Asan Medical Center, University of Ulsan College of Medicine, Seoul, Korea.

${ }^{5}$ Division of General Medicine and Primary Care, Department of Medicine, Brigham and Women's Hospital, Boston,

Massachusetts.

\section{Abstract}

Background: This study was conducted to analyze the usage pattern of a hospital-tethered mobile personal health records ( $m$-PHRs) application named My Chart in My Hand (MCMH) and to identify user characteristics that influence $m-P H R$ usage. Materials and Methods: Access logs to MCMH and its menus were collected for a total of 18 months, from August 2011 to January 2013. Usage patterns between users without a patient identification number (ID) and users with a patient ID were compared. Users with a patient ID were divided into light and heavy user groups by the median number of monthly access. Multiple linear regression models were used to assess MCMH usage pattern by characteristics of MCMH user with a patient ID. Results: The total number of MCMH logins was 105,603, and the median number of accesses was 15 times. Users ( $\mathrm{n}=7,096)$ mostly accessed the "My Chart" menu, but “OPD [outpatient department] Service Support" and "Health Management” menus were also frequently used. Patients with chronic diseases, experience of hospital visits including emergency room and $O P D$, and age group of 0-19 years were more frequently found among users with a patient ID $(\mathrm{n}=2,186)(\mathrm{p}<0.001)$. A similar trend was found in the heavy user group $(\mathrm{n}=1,123)$. Submenus of laboratory result, online appointment, and medication lists that were accessed mostly by users with a patient ID were associated with OPD visit and chronic diseases. Conclusions: This study showed that focuses on patients with chronic disease and more hospital visits and empowerment functions in a tethered $m-P H R$ would be helpful to pursue the extensive use.

Key words: personal health record, mobile health, consumer health information, chronic disease, empowerment

\section{Introduction}

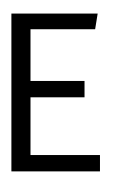

lectronic medical records (EMRs) can enhance communication, increase accessibility to medical information for patients, reduce medical errors, and improve patient safety. However, patient participation and access to EMRs are still limited because EMRs are primarily designed for healthcare providers, not for patients. ${ }^{1-3}$ Personal health records (PHRs) can meet patients' needs of active participation and access to their own medical information. ${ }^{4}$ By using PHRs, patients can more easily access and manage the medical information provided by hospitals. ${ }^{3-6}$ Moreover, tools for the management of chronic diseases can be provided. In addition, if patients and medical institutions agree with integration of data, the medical information of several different medical institutions would be integrated. ${ }^{7}$ Ideally, patients would control their own medical information by using PHRs, and thus PHRs are regarded as a paradigm shift and the core of patient-oriented health and medical services. ${ }^{8-11}$

Recently, mobile health has become more widespread due to the popularization of smartphones. ${ }^{12,13}$ Mobile PHRs (m-PHRs) that use a smartphone or tablet device have also been developed to provide more accessibility and mobility for patients' health. ${ }^{14}$ Smartphones can remove the barriers that

(C) The Author(s) 2015; Published by Mary Ann Liebert, Inc. This Open Access article is distributed under the terms of the Creative Commons Attribution Noncommercial License (http://creativecommons.org/licenses/by-nc/4.0/) which permits any noncommercial use, distribution, and reproduction in any medium, provided the original author(s) and the source are credited. 


\section{LEE ET AL.}

prevent patients from using PHRs by increasing mobility, accessibility, and connectivity. ${ }^{15,16}$

PHRs should be user-friendly and provide services desired by patients. ${ }^{9,17}$ To make m-PHRs more valuable tools for patient-centered care, further studies are needed to investigate $\mathrm{m}$-PHR user experiences, usage patterns, and user characteristics. Many studies have examined the characteristics and disparities of PHR users, whereas only small numbers of studies have analyzed the characteristics of m-PHR users. ${ }^{18}$

Asan Medical Center (AMC), Seoul, Korea, the largest tertiary hospital in the country with about 2,700 registered inpatient beds and a large in-house hospital information system, developed a tethered m-PHR application (app) called My Chart in My Hand (MCMH) and released it on Google Play in January $2011 .^{19}$ The present study aimed to analyze the usage pattern of the MCMH app and to identify the user characteristics that affect $\mathrm{m}$-PHR access.

\section{Materials and Methods}

\section{INTRODUCTION TO THE MCMH APP}

The MCMH project was started in February 2010 to help patients view and manage their own health records themselves by using mobile devices. The MCMH app was developed by collaboration between the Ubiquitous Health Center at AMC, which was established to support mobile and e-health research and service, and a telecommunications company in Korea. The development process of the MCMH app is shown in Figure 1. It took 11 months to design and build the app. When

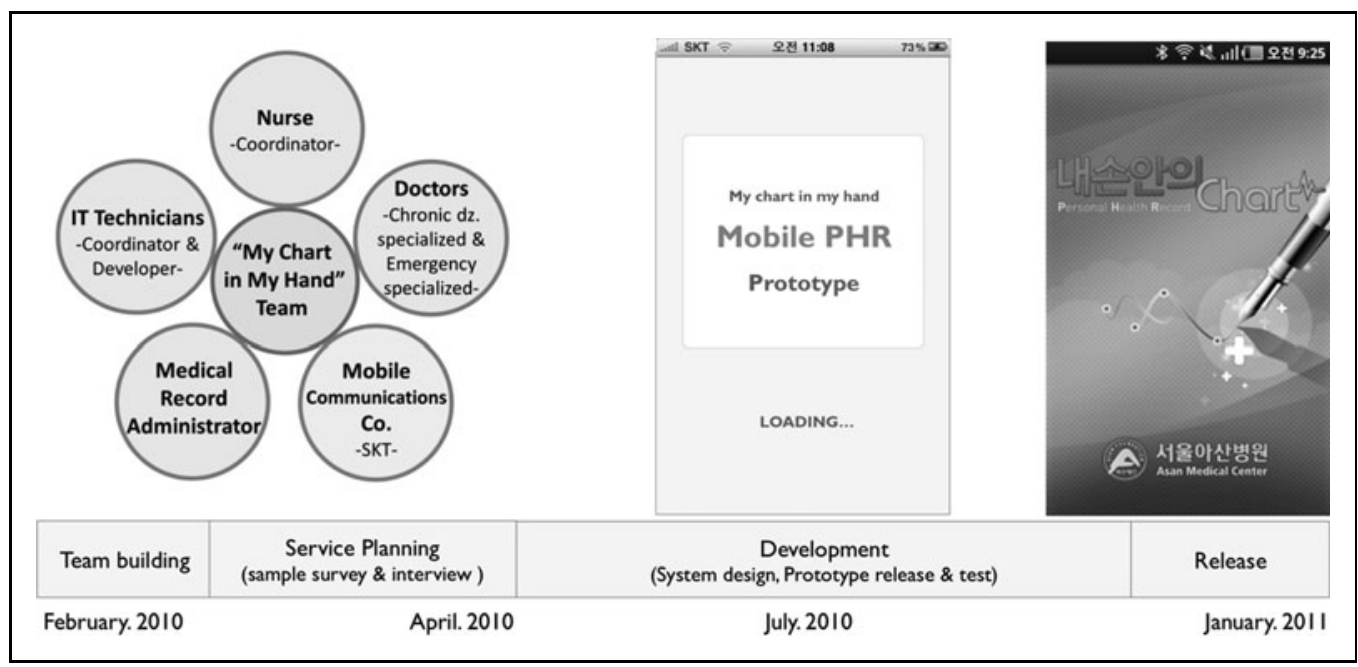

Fig. 1. The development process of the My Chart in My Hand application. The My Chart in My Hand team was organized with doctors, a nurse, information technology technicians, a medical record administrator, and a mobile communication company (Co.) in February 2010. It took 11 months to design and develop My Chart in My Hand, which was released on Google Play in January 2011. IT, information technology; dz., disease; PHR, personal health record. designing the app, we considered people from their 20 s to their 50s, who could use a smartphone with relative ease and have more interest in their health information due to chronic disease, etc., as the target customer group. Key informant interviews were undertaken with participants who experienced treatment processes in the hospital, such as patients, doctors, and nurses. Based on the interview results, the MCMH app was mainly designed for chronic disease patients who could unrestrictedly use smartphones and functions that attract patients to access their health information. The monitoring system that shows a user's log data was developed in August 2011.

Screenshots of MCMH are shown in Figure 2. The app largely contains five menus categorized by contents and purposes. The "My Chart" categorized menu shows patients' health information from the hospital, including laboratory results, problem lists, allergies, and medication history. Users can also manually enter medical information, including laboratory results, allergies, medication lists, and vital signs from other hospitals or clinics or self-measurements, but these data are managed separately from AMC data. This option was designed for patients to manage their medical information from various sources. The "Health Management" categorized menu provides diary tools for body weight, glucose, and blood pressure, as well as medical calculators such as those for body mass index, cardiovascular disease risk in 10 years, and metabolic syndrome risk. The "Medication Management" categorized menu includes medication schedulers and reminders of when to take medicines. The "OPD [outpatient department] Service Support" categorized menu offers appointments for the ambulatory care center and provides a patient-centered and convenient function that shows the patient's order in the waiting list of a doctor's office. The "Health Information" categorized menu gives various education materials on health information related to daily life. Because of healthcare environmental limitations and legal restrictions in Korea, MCMH did not include some options that are popular in other PHRs in the United States, such as prescription refilling and secure messaging between patients and physicians. ${ }^{20-22}$ 


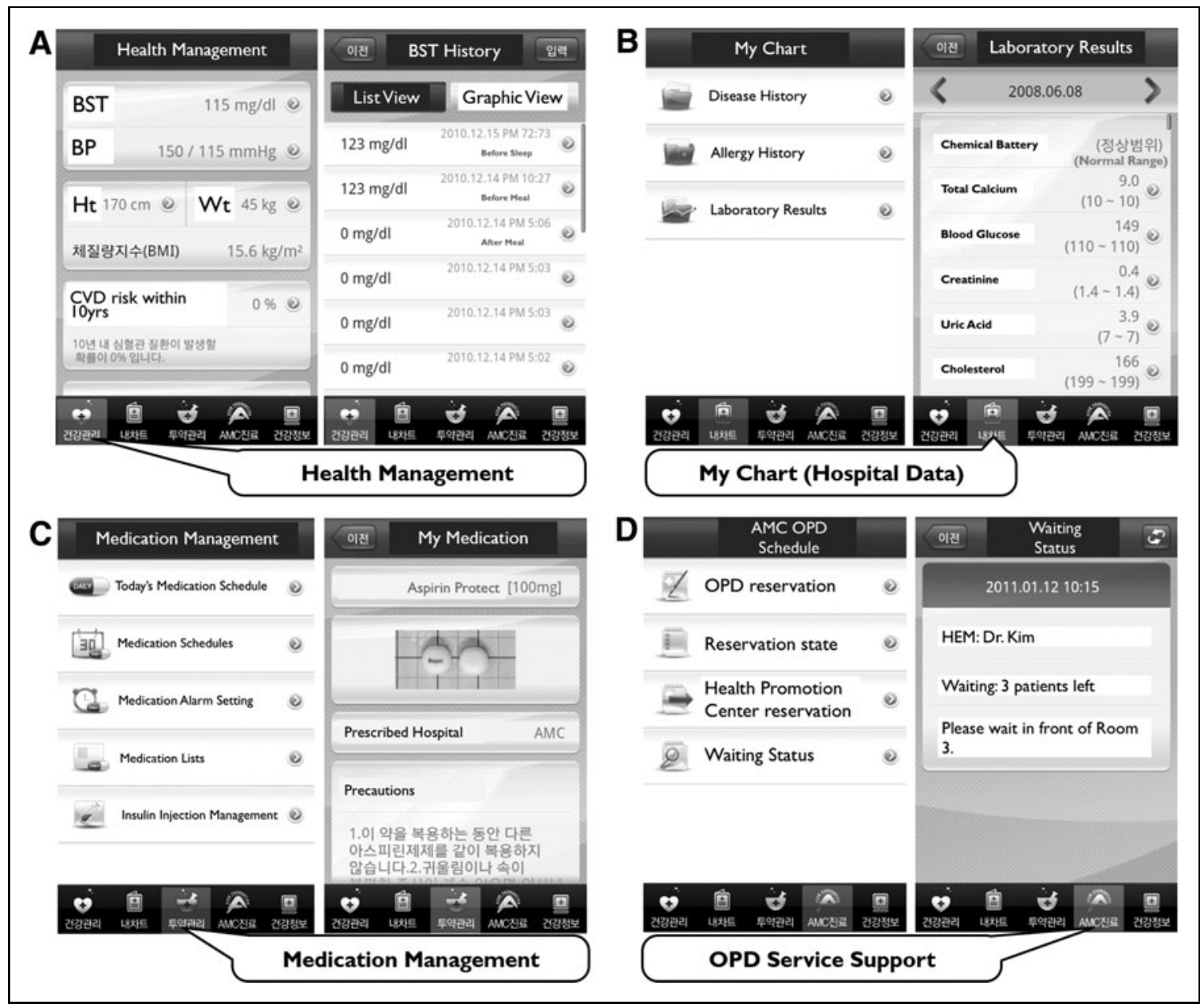

Fig. 2. Screenshots of the My Chart in My Hand application: (A) "Health Management," (B) "My Chart," (C) "Medication Management," and (D) "Outpatient Department [OPD] Service Support" menus. AMC, Asan Medical Center; BMI, body mass index; BP, blood pressure; BST, blood sugar test; CVD, cardiovascular disease; HEM, Department of Hematology; Ht, height; OPD, outpatient department; Wt, weight.

Because MCMH is a tethered m-PHR app that communicates with the hospital database by patient identification number (ID) of AMC, the connected AMC database services like "My Chart" and "OPD Service Support" are provided exclusively for MCMH users with a patient ID. MCMH users without a patient ID technically can download MCMH but are limited in using the connected AMC database services.

\section{STUDY DESIGN AND PROCEDURE}

Approval for this study was obtained from the Institutional Review Board of AMC.

The number of MCMH users who downloaded the app with or without a patient ID exceeded 7,000 in January 2013. To assess the usage pattern of MCMH, users $(n=4,910)$ without a patient ID and users $(n=2,186)$ with a patient ID who downloaded MCMH from August 2011 to January 2013 were selected.
To analyze the factors that affect the use of MCMH including the services that are connected with hospital database, only users with a patient ID were selected. The 2,186 users with a patient ID were grouped as either "light users" $(n=1,063)$ who accessed MCMH below the median of two times per a month or "heavy users" $(n=1,123)$ who logged in at or above the median of monthly access.

Users' information was collected from the hospital database and mobile server. From the hospital database, users' gender, age, residence, and health information including hospital visits (OPD, emergency room [ER], and hospitalization) and the presence of chronic diseases were gathered. From the mobile server, users' logged data for MCMH and categorized menus were assembled except for the "Health Information" menu, which was not included in the log monitoring system. 


\section{LEE ET AL.}

Distance from AMC to patient residence was grouped as "short distance" if the patient lived near AMC in the capital region and "long distance" if the patient lived in the non-capital region. We used the definitions of the Korea Center for Disease Control and Prevention, which includes cancer (C00-C97), diabetes (E10-E14), hypertensive disease (I20-I51), cerebrovascular disease (I60-I69), chronic lower respiratory disease (J40-J47), and liver disease $(\mathrm{K} 70-\mathrm{K} 76) .^{23,24}$ All diseases are classified by the 10th International Classification of Diseases.

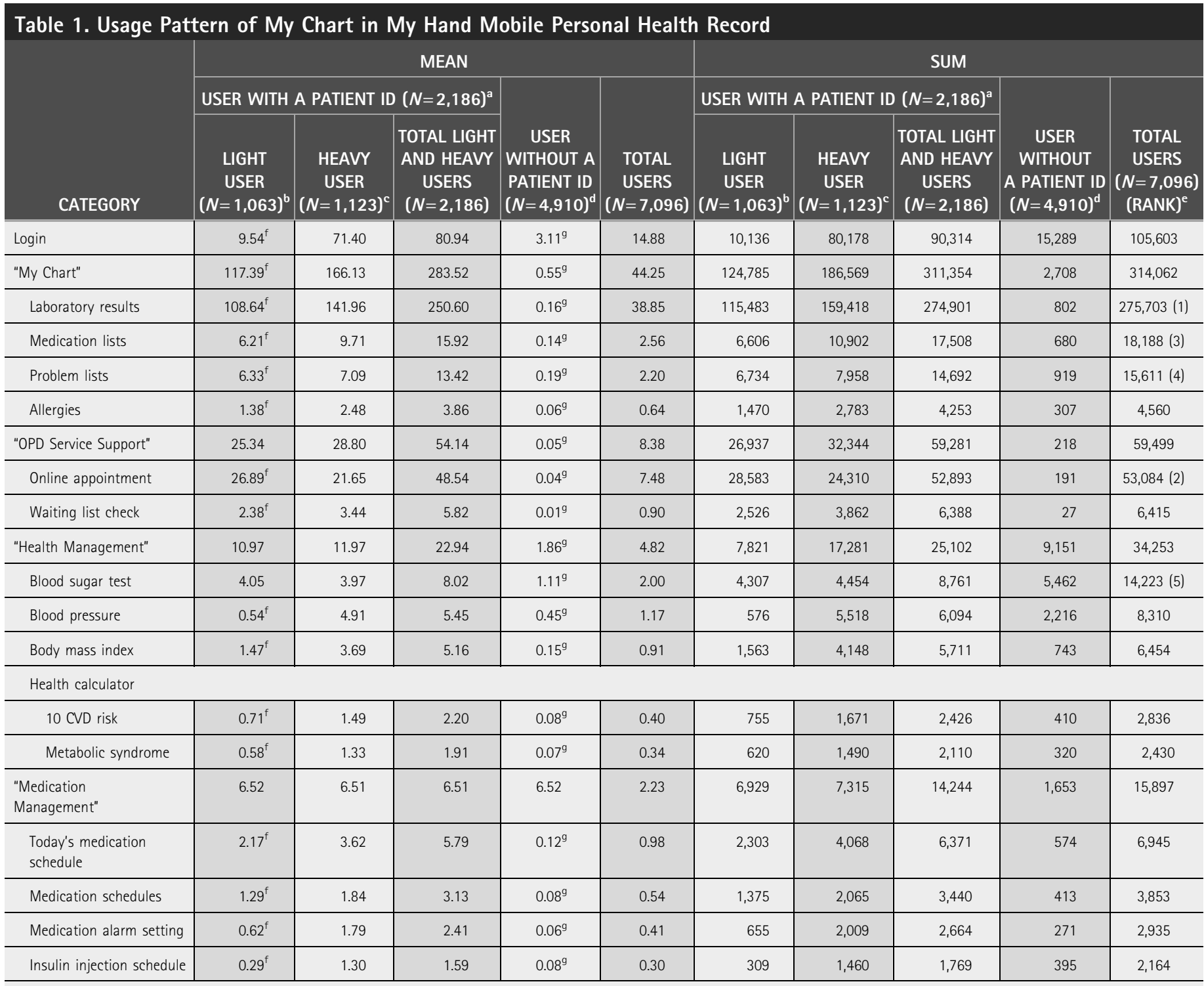

${ }^{\mathrm{a}} \mathrm{A}$ user with a patient identification number (ID) who is able to fully access My Chart in My Hand.

${ }^{\mathrm{b}} \mathrm{A}$ light user is someone who accessed My Chart in My Hand at or below the median (less than two times per a month) of the users with a patient ID.

${ }^{\mathrm{C}} \mathrm{A}$ heavy user is someone who accessed My Chart in My Hand above the median (two or more times per a month) of the users with a patient ID.

${ }^{\mathrm{d} A}$ user without a patient ID who is able to fully access My Chart in My Hand except for "My Chart" and "Outpatient department [OPD] Service Support" categorized menus that communicate with the hospital database.

${ }^{\text {e}}$ Ranked in order of popularity except for categorized menus such as the "My Chart" menus.

fThe $p$ values $(<0.05)$ indicate significant difference in number of logins or accesses to each menu between the light user and heavy user with a patient ID by $t$ test. ${ }^{9}$ The $p$ values $(<0.05)$ indicate significant difference in number of logins or accesses to each menu between the user without a patient ID and the user with a patient ID by $t$ test. CVD, cardiovascular disease. 
Users' characteristics and access logs were compared between the two groups (light and heavy users) to identify characteristics affecting MCMH usage.

\section{STATISTICAL ANALYSIS}

Descriptive statistics, correlations, and stepwise multiple linear regression analyses were computed with the SPSS version 23.0 statistical software package (IBM, Armonk, NY). Significance level was set at $p<0.05$.

\section{Results}

\section{USE OF MCMH}

During the 1.5-year study period, the total number of MCMH logins was 105,603. Table 1 shows the number of accesses to the menus of MCMH in detail. The most popular categorized menu in total user was the "My Chart" (total access $=314,062$; mean access $=44.25$ times). The most visited menu was "Laboratory Results" (total access $=275,703$; mean access $=38.85$ times), followed by the "Online Appointment," "Medication Lists," "Problem List," and "Blood Sugar Test" menus.

Compared with the users without a patient ID, the users with a patient ID accessed all of menus much more frequently. The most popular menu among the users with a patient ID was communication with the hospital database based on the patient ID, such as "Laboratory Results" (mean access $=250.60$ times versus mean access $=0.16$ times), "Online Appointment" (mean access $=48.54$ times versus mean access $=0.04$ times), and "Medication Lists" (mean access $=15.92$ times versus mean access $=0.14$ times).

In comparison with light users among users with a patient ID, heavy users logged into the MCMH app more frequently (mean access $=71.40$ times versus mean access $=9.54$ times). Heavy users accessed most of the menus except for "Blood Sugar Test" ( mean access $=3.97$ times versus mean access $=4.05$ times) and "Online Appointment" (mean access $=21.65$ times versus mean access $=26.89$ times) more often.

\section{DEMOGRAPHIC PROFILE OF THE USERS WITH A PATIENT ID}

General characteristics including gender, age, distance to the hospital from the residence, and health-related attributes like hospital visit frequency and presence of chronic diseases were gathered for all study subjects $(n=2,186)$ who had a patient ID (Table 2). There were significant differences in general characteristics and health-related attributes between the heavy and light user groups $(p<0.05)$.

Heavy users had a higher proportion of males than light users (55.3\% versus 50.4\%; $p=0.022$ ). The distribution of age

\begin{tabular}{|c|c|c|c|c|}
\hline \multirow[b]{2}{*}{$\begin{array}{l}\text { VARIABLE, } \\
\text { CATEGORY }\end{array}$} & \multicolumn{3}{|c|}{$N(\%$ OF ROW $)$} & \multirow[b]{2}{*}{$\begin{array}{c}P \\
\text { VALUE }\end{array}$} \\
\hline & $\begin{array}{l}\text { LIGHT USER } \\
(N=1,063)^{\mathrm{a}}\end{array}$ & $\begin{array}{l}\text { HEAVY USER } \\
(N=1,123)^{b}\end{array}$ & $\begin{array}{c}\text { TOTAL } \\
(N=2,186)\end{array}$ & \\
\hline Gender & & & & $0.022^{c}$ \\
\hline Male & $536(50.4)$ & $621(55.3)$ & $1,157(52.9)$ & \\
\hline Female & 527 (49.6) & $502(44.7)$ & $1,029(47.1)$ & \\
\hline Age (years) & & & & $<0.001^{c}$ \\
\hline $0-19$ & $80(7.5)$ & 218 (19.4) & $298(13.7)$ & \\
\hline $20-39$ & 563 (53.0) & 439 (39.1) & $1,002(45.8)$ & \\
\hline $40-59$ & 327 (30.8) & 369 (32.9) & 696 (31.8) & \\
\hline$\geq 60$ & $93(8.7)$ & $97(8.6)$ & 190. (8.7) & \\
\hline Mean $\pm S D$ & $37.60 \pm .15 .18$ & $35.76 \pm 17.65$ & $36.6 \pm 16.5$ & \\
\hline $\begin{array}{l}\text { Long distance } \\
\text { to the hospital }\end{array}$ & & & & $<0.001^{\mathrm{c}}$ \\
\hline Yes & 317 (29.8) & 431 (38.4) & 748 (34.2) & \\
\hline No & 746 (70.2) & 692 (61.6) & 1,438 (65.8) & \\
\hline $\begin{array}{l}\text { Chronic disease } \\
\text { patient }\end{array}$ & & & & $<0.001^{\mathrm{c}}$ \\
\hline Yes & $373(35.1)$ & 963 (85.8) & $1,336(61.1)$ & \\
\hline No & $690(64.9)$ & $160(14.2)$ & 850 (38.9) & \\
\hline $\begin{array}{l}\text { Experience of } \\
\text { hospitalization }\end{array}$ & & & & $<0.001^{\mathrm{c}}$ \\
\hline Yes & $695(65.4)$ & $563(50.1)$ & $1,258(57.5)$ & \\
\hline No & $368(34.6)$ & 560 (49.9) & 928 (42.5) & \\
\hline
\end{tabular}

Number of hospital visits (mean \pm SD)

\begin{tabular}{l|c|c|c|c}
\hline ER & $0.55 \pm .1 .71$ & $1.57 \pm 2.92$ & $1.07 \pm 2.46$ & $<0.001^{d}$ \\
\hline OPD & $10.46 \pm 11.48$ & $20.22 \pm 15.65$ & $15.48 \pm 14.62$ & $<0.001^{d}$ \\
\hline
\end{tabular}

Data are number of subjects (\%)

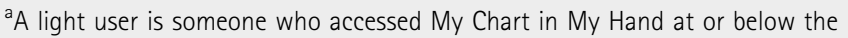
median (less than two times per month) of the users with a patient ID.

${ }^{b}$ A heavy user is someone who accessed My Chart in My Hand above the median (two or more times per month) of the users with a patient ID.

${ }^{\mathrm{C}}$ By chi-squared test.

${ }^{\mathrm{d}}$ By $t$ test.

$E R$, emergency room; OPD, outpatient department; SD, standard deviation.

groups differed between total heavy users and light users $(p<0.001)$. The users in the age group of $0-19$ years made up a relatively larger portion of the heavy group than of the light user group (19.4\% versus 7.5\%). The heavy user group had a smaller portion of the age group of 20-39 years than the light 


\section{LEE ET AL.}

user group (39.1\% versus 53.0\%). There were more patients whose residence was in a long distance from the hospital in the heavy user group than in the light user group $(38.4 \%$ versus $29.8 \% ; p<0.001)$, however, more than half of users in each group lived in a short distance from the hospital. Chronic disease patients were more likely to be heavy users $(85.8 \%$ versus $35.1 \% ; p<0.001)$. Heavy users also differed from light users in experiences of hospitalization (50.1\% versus $65.4 \%$; $p<0.001)$. Heavy users had more hospital visits $(p<0.001)$.

\section{CHARACTERISTICS OF USERS WITH A PATIENT ID INFLUENCING MCMH USAGE}

To analyze the interconnections between MCMH usage and characteristics of users with patient ID, we performed correlation analyses (Table 3). Most of the user's characteristics, including gender, distance to the hospital, hospital visit frequency, presence of chronic diseases, and age group except for the 40-59-year-old age group, were significantly interconnected with MCMH access $(p<0.05)$. The variables of chronic disease patient, ER visit, and OPD visit were positively associated with MCMH accesses.

We conducted stepwise multiple linear regression analyses to identify significant predictors of MCMH users with a patient
ID including the variables that appeared to correlate with MCMH access (i.e., gender, distance to the hospital, hospital visit frequency, presence of chronic diseases, and age groups except for the 40-59-year-old age group) (Table 4). The variable of 20-39-year-old age group was excluded from the regression analyses by the stepwise method. MCMH usage of users with a patient ID was predicted best by OPD visit, with further positive influences of chronic disease patient, 0-19year-old age group, ER visit, and long distance to the hospital and negative influences of hospitalized experience, age group over 60 years old, and female gender $(p<0.001)$. These variables explain $38.8 \%$ of variance.

To analyze significant predictors of heavy user characteristics, we performed stepwise multiple linear regression analyses including the variables that appeared to interconnect with MCMH access (Table 5). The variables of long distance to the hospital, gender, age group of 20-39 years old, and age group over 60 years old were excluded from the regression analyses by the stepwise method. MCMH usage of heavy users was also predicted best by OPD visit, and other influencing factors were similar in slightly different order from the predictors of MCMH users with a patient ID. These variables explain $29.9 \%$ of variance.

\begin{tabular}{|c|c|c|c|c|c|c|c|c|c|c|c|}
\hline & $\begin{array}{l}\text { MCMH } \\
\text { ACCESS } \\
\text { (LOGIN) }\end{array}$ & GENDER & $\begin{array}{c}0-19 \\
\text { YEARS } \\
\text { OLD }\end{array}$ & $\begin{array}{c}20-39 \\
\text { YEARS } \\
\text { OLD }\end{array}$ & $\begin{array}{c}40-59 \\
\text { YEARS } \\
\text { OLD }\end{array}$ & $\begin{array}{c}\text { OVER } 60 \\
\text { YEARS }\end{array}$ & $\begin{array}{c}\text { DISTANCE } \\
\text { TO THE } \\
\text { HOSPITAL }\end{array}$ & $\begin{array}{l}\text { CHRONIC } \\
\text { DISEASE } \\
\text { PATIENT }\end{array}$ & HOSPITALIZATION & $\begin{array}{c}\text { ER } \\
\text { VISITS }\end{array}$ & $\begin{array}{l}\text { OPD } \\
\text { VISITS }\end{array}$ \\
\hline $\begin{array}{l}\text { MCMH access } \\
\text { (login) }\end{array}$ & 1.000 & & & & & & & & & & \\
\hline Gender & $-0.055^{a}$ & 1.000 & & & & & & & & & \\
\hline $0-19$ years & $0.296^{b}$ & -0.033 & 1.000 & & & & & & & & \\
\hline 20-39 years & $-0.172^{b}$ & $0.218^{b}$ & $-0.365^{b}$ & 1.000 & & & & & & & \\
\hline $40-59$ years & -0.008 & $-0.174^{b}$ & $-0.272^{b}$ & $-0.629^{b}$ & 1.000 & & & & & & \\
\hline Over 60 years & $-0.044^{b}$ & $-0.057^{\mathrm{a}}$ & $-0.123^{b}$ & $-0.284^{b}$ & $-0.211^{b}$ & 1.000 & & & & & \\
\hline $\begin{array}{l}\text { Distance to the } \\
\text { hospital }\end{array}$ & $0.085^{b}$ & -0.010 & $0.079^{b}$ & $-0.044^{\mathrm{a}}$ & $-0.048^{\mathrm{a}}$ & $0.062^{\mathrm{a}}$ & 1.000 & & & & \\
\hline $\begin{array}{l}\text { Chronic disease } \\
\text { patient }\end{array}$ & $0.409^{b}$ & $-0.118^{b}$ & 0.035 & $-0.202^{b}$ & $0.122^{b}$ & $0.113^{b}$ & $0.116^{b}$ & 1.000 & & & \\
\hline Hospitalization & $-0.242^{b}$ & 0.026 & -0.026 & $0.053^{\mathrm{a}}$ & -0.023 & -0.024 & -0.017 & $-0.102^{b}$ & 1.000 & & \\
\hline ER visits & $0.351^{b}$ & -0.001 & $0.273^{b}$ & $-0.112^{b}$ & $-0.073^{b}$ & -0.014 & -0.001 & $0.186^{b}$ & $-0.094^{b}$ & 1.000 & \\
\hline OPD visits & $0.460^{b}$ & $0.073^{\mathrm{a}}$ & $0.204^{b}$ & $-0.138^{b}$ & -0.016 & 0.023 & $-0.043^{\mathrm{a}}$ & $0.332^{b}$ & $-0.125^{b}$ & $0.310^{b}$ & 1.000 \\
\hline
\end{tabular}

${ }^{a} p<0.05,{ }^{b} p<0.001$.

ER, emergency room; MCMH, My Chart in My Hand; OPD, outpatient department. 
Table 4. Multiple Regression Analysis to Identify Significant Characteristics of the My Chart in My Hand (MCMH) Users with a Patient Identification Number That Are Associated with MCMH Access

\begin{tabular}{|c|c|c|c|c|}
\hline MODEL $^{\mathrm{a}}$ & B & $\beta$ & $T$ & $P$ \\
\hline (Constant) & 1.652 & & 27.674 & $<0.001$ \\
\hline OPD visit ${ }^{b}$ & 0.014 & 0.276 & 14.591 & $<0.001$ \\
\hline Chronic disease patient $^{c}$ & 0.413 & 0.263 & 14.307 & $<0.001$ \\
\hline $0-19$ years old $^{d}$ & 0.380 & 0.170 & 9.529 & $<0.001$ \\
\hline Experience of hospitalization ${ }^{e}$ & -0.249 & -0.161 & -9.494 & $<0.001$ \\
\hline ER visit ${ }^{\dagger}$ & 0.048 & 0.155 & 8.482 & $<0.001$ \\
\hline Over 60 years old ${ }^{g}$ & -0.181 & -0.067 & -3.906 & $<0.001$ \\
\hline Long distance to the hospital $^{h}$ & 0.088 & 0.054 & 3.185 & 0.001 \\
\hline Female gender & -0.058 & -0.038 & -2.208 & 0.027 \\
\hline
\end{tabular}

${ }^{a} R=0.623 ; R^{2}=0.388 ;$ adjusted $R^{2}=0.386 ; p<0.001$. The variable $20-39$ years was excluded by stepwise regression analyses.

${ }^{b}$ Each additional increment in outpatient department (OPD) visits was associated with a 0.014 times per month increase in MCMH access $(p<0.001)$.

${ }^{c} A$ chronic disease patient's access to MCMH was 0.413 times/month higher than that of a non-chronic disease patient $(p<0.001)$.

${ }^{\mathrm{d}} \mathrm{MCMH}$ access of the $0-19$-year-old age group was 0.380 times higher than those of other age groups $(p<0.001)$

${ }^{\mathrm{e}} \mathrm{A}$ patient with experience of hospitalization was associated with a 0.249 times decrease in MCMH access $(p<0.001)$

${ }^{f}$ Each additional emergency room (ER) visit was associated with a 0.048 times increase in MCMH access $(p<0.001)$.

${ }^{9} \mathrm{MCMH}$ access of the age group over 60 years of age was 0.181 times lower than those of other age groups $(p<0.001)$.

${ }^{\mathrm{h}} \mathrm{A}$ long distance to the hospital was associated with a 0.088 times increase in MCMH access $(p=0.001)$

'MCMH access of females was 0.058 times lower than that of males ( $p=0.027)$.

We conducted stepwise multiple linear regression analyses to identify significant characteristics of MCMH users with a patient ID on popular submenus including "Laboratory Results," "Online Appointment," and "Medication Lists" (Table 6). The access of "Laboratory Results" was explained with weak power $\left(R^{2}=0.038\right)$ by chronic disease patient and further by more OPD visits, by less 60-year-old age group, and by more ER visits. The access of "Online Appointment" was explained with weak power $\left(R^{2}=0.023\right)$ best by fewer ER visits and more OPD visits, with further negative influences of hospitalization and age group of 0-19 years old and positive influences of chronic disease patient. The access of "Medication Lists" was explained by chronic disease patient, more OPD visits, and no hospitalization $\left(R^{2}=0.083\right)$.
Table 5. Multiple Regression Analysis to Identify

Significant Characteristics of the Heavy My Chart

in My Hand (MCMH) Users with a Patient Identification Number That Are Associated with MCMH Access

\begin{tabular}{|c|c|c|c|c|}
\hline MODEL $^{\mathrm{a}}$ & B & $\beta$ & $T$ & $P$ \\
\hline (Constant) & 2.100 & & 34.234 & $<0.001$ \\
\hline OPD visit ${ }^{b}$ & 0.014 & 0.290 & 10.986 & $<0.001$ \\
\hline $0-19$ years $^{c}$ & 0.405 & 0.207 & 7.740 & $<0.001$ \\
\hline ER visit ${ }^{d}$ & 0.054 & 0.205 & 7.617 & $<0.001$ \\
\hline Experience of hospitalization ${ }^{e}$ & -0.235 & -0.152 & -5.999 & $<0.001$ \\
\hline Chronic disease patient ${ }^{f}$ & 0.131 & 0.059 & 2.326 & 0.020 \\
\hline
\end{tabular}

${ }^{\mathrm{a}} R=0.547 ; R^{2}=0.299 ;$ adjusted $R^{2}=0.296 ; p<0.001$. The variables $20-39$ years, over 60 years, long distance to the hospital, and gender were excluded by stepwise regression analyses.

${ }^{b}$ Each additional increment in outpatient department (OPD) visits was associated with a 0.014 times increase in MCMH access $(p<0.001)$.

${ }^{c} M C M H$ access of the 0 -19-year-old age group was 0.405 times higher than those of other age groups $(p<0.001)$.

${ }^{d}$ Each additional emergency room (ER) visit was associated with a 0.054 times increase in MCMH access $(p<0.001)$.

${ }^{\mathrm{e}} \mathrm{A}$ patient with experience of hospitalization was associated with a 0.235 times decrease in MCMH access $(p<0.001)$.

${ }^{\mathrm{f}} \mathrm{A}$ chronic disease patient's access to MCMH was 0.131 times higher than that of a non-chronic disease patient $(p=0.020)$.

\section{Discussion}

$\mathrm{m}$-PHR could be the hub of $\mathrm{m}$-health because it contains patient health information, is in the hands of the patients themselves, and can be directly connected to peripheral devices such as activity trackers and blood sugar test devices. ${ }^{25,26}$ It is expected that the efficiency and effectiveness of m-PHRs will be increased by the use of sensors, cameras, recording functions, or barcode reader applications in smartphones. ${ }^{27}$ For patient empowerment and safety, integrated m-PHRs that interact with EMRs are the best choice. ${ }^{2}$ However, when integrated m-PHRs are not available, a tethered m-PHR that shares some medical information through EMRs can be the next, most suitable choice. ${ }^{2}$

In MyChart, the Web-based PHR of the Cleveland Clinic, about 75\% (450,000 users) of the members have used their PHR at least once. ${ }^{28}$ In the case of Kaiser Permanente, the three most visited features of their My Health Manager PHR from 2004 to 2007 were the laboratory test review, prescription refills, and e-mail messages to providers. ${ }^{14,25,28-30}$ In the stand-alone PHR that depends solely on patient-entered data as the trusted medical record, "Laboratory Results" was the least frequently used information menu, and "Medication 


\section{LEE ET AL.}

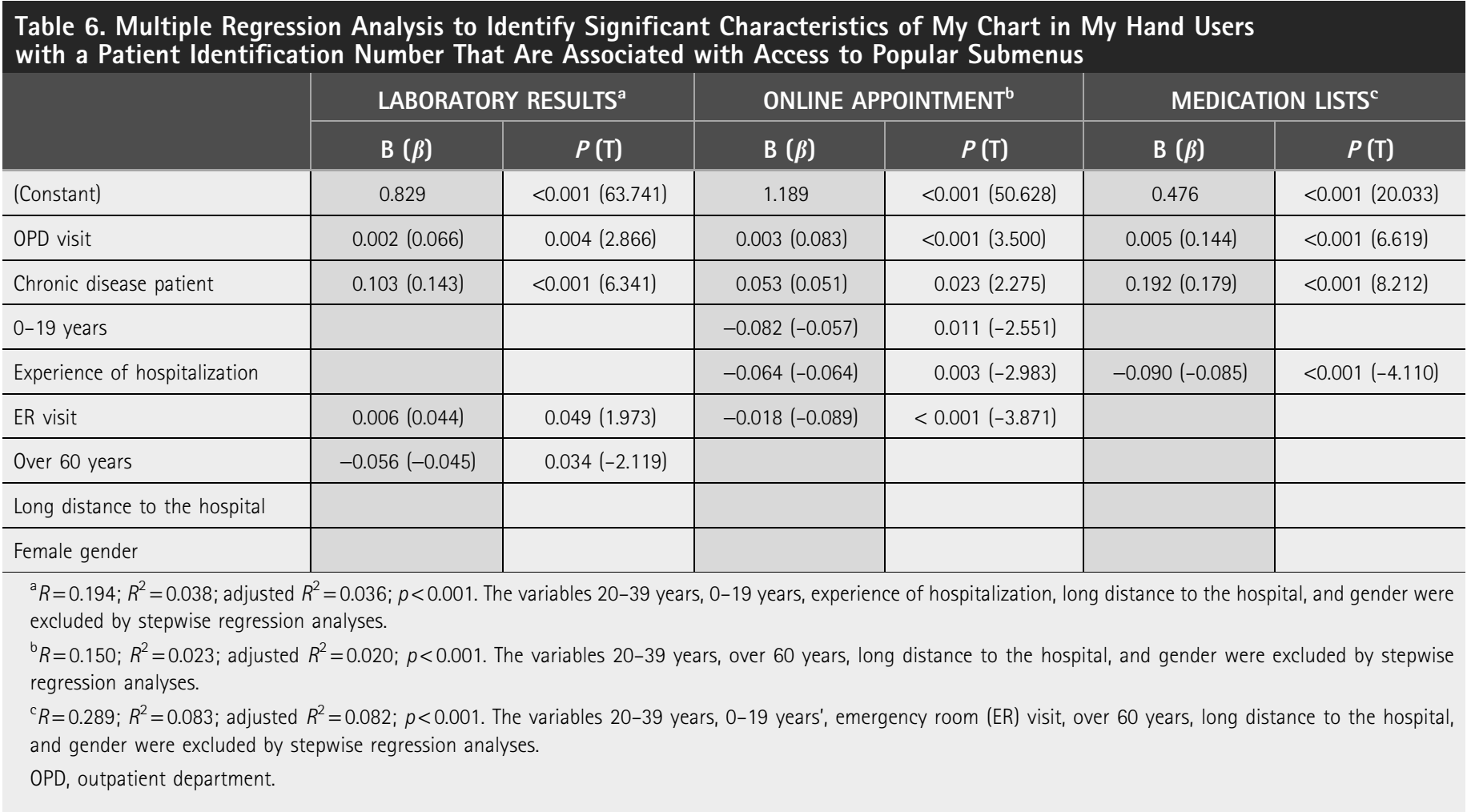

Information" was the most visited menu. ${ }^{31-33}$ In our current study, like the My Health Manager, the laboratory results option was the most viewed menu that and was accessed a total of 275,703 times during the study period (about 15,317 times/month) (Table 1). It is interesting that the OPD online appointment function, which is also available at the AMC homepage, was ranked second to laboratory results, followed by medication lists and problem lists. Not only menus linked to the hospital information system that are characteristics of a tethered PHR but also menus that are characteristics of a stand-alone PHR were well used by some patients, including the "Health Management" categorized menu for blood sugar test (about 790 times/month), blood pressure (about 462 times/month), and body mass index (about 359 times/month) and "Medication Management" categorized menu for medication schedules (about 214 times/month).

\section{CHARACTERISTICS OF USERS WITH A PATIENT ID INFLUENCING MCMH USAGE}

Increased access to MCMH was significantly associated with an increased use of the "OPD Service Support," "Health Management," and "My Chart" categorized menus. Although the "OPD Service Support" categorized menu was not the most visited menu, the users of this service were more active MCMH users. Users who made more visits to the hospital or had a chronic disease accessed MCMH more often. These results were in agreement with those of other studies that showed a strong correlation between the degree of sickness, including numbers of diagnoses and clinical visits, and frequency of PHR use. ${ }^{28,34,35}$

Regarding the age of PHR users, previous studies provided contradictory findings, such as disparities in specific age groups or similarities among all ages. ${ }^{28,36,37}$ More than $80 \%$ of MCMH users with a patient ID were between 20 and 59 years old. However, the users in the 0-19-year-old age group showed a higher percentage of heavy users. This may be explained by the observation that about 53.2\% (116 persons) of the 0-19-year-old age group in heavy users have a chronic disease, including malignant neoplasm and leukemia. This result may be because their parents accessed MCMH on the behalf of younger patients, especially children, even though such access was technically not allowed. Regardless of the cause of the prevalent use of MCMH in younger patients, it may be important to focus on young people to promote the use of MCMH and similar PHR apps.

\section{LESSON LEARNED}

We could learn several lessons from analysis of the usage pattern and user characteristics. First, users want not only to 


\section{WHICH USERS SHOULD BE THE FOCUS OF M-PHRS?}

see their medical information that is provided by the hospital, but also to engage with their health management. Second, users are interested in the hospital-supporting functions like "Online Appointment." Even though it is difficult to predict, other useful hospital-supporting functions, if provided, may also be popular functions of an m-PHR. Third, the m-PHR must be focused or upgraded for active users who access and use the m-PHR more frequently. Chronic disease patients who visited the hospital frequently showed increased access to the m-PHR. Thus, specific functions or menus for chronic disease patients, such as cancer marker results, health tools for other chronic diseases, and daily care plans for inpatients, should be developed and provided. Specific PHRs for cancer, asthma, hospitalized, and pediatric patients will also be useful. Finally, functions that use exact user information and location can be useful in m-PHRs. For example, the "Waiting List Check" function in this study used patient OPD appointment data, their arrival information to the OPD, and the OPD schedule information system.

\section{LIMITATIONS AND FUTURE STUDIES}

This study has some limitations that also represent opportunities for future work. We only examined logged data, not actual behavior. Although a robust body of evidence demonstrates that intentions predict behavior, ${ }^{38}$ thereby mitigating this concern, there may still be unplanned accesses due to an unstable Internet connection, unintended menu selection, or other events. We did not analyze other possible factors affecting use of the m-PHR, include socioeconomic status, the required time to visit AMC, encouragement by attending doctors and family, technology anxiety, ease of use, and health literacy. ${ }^{28,39,40}$ Because such data cannot be retrieved from a hospital information system, new research design is needed, including a patient survey. In addition, further research will be necessary to analyze for focused use of MCMH-specific functions such as "Waiting List Check," a unique patient-centered menu, even though the access was not very popular, and for the divide between hospitalized patients and OPD and ER patients of "My Chart" to engage the patients in their plan of care.

\section{Conclusions}

This study may indicate ways for healthcare providers and technology companies to develop helpful tethered m-PHR apps for patients. It showed the usage characteristics that focus on chronic disease patients that enabled active use of the tethered m-PHR app and also showed which empowerment and engagement function in the app would be helpful to pursue the extensive use.

\section{Acknowledgments}

We thank SK Telecom Co., Ltd. for being as an alliance partner for helping with the development of the MCMH app. This research was supported by the Basic Science Research Program through the National Research Foundation of Korea funded by the Ministry of Science, ICT \& Future Planning (grant NRF-2012R1A1A1014529).

\section{Disclosure Statement}

No competing financial interests exist.

\section{REFERENCES}

1. Tang PC, Lansky D. The missing link: Bridging the patient-provider health information gap. Health Aff (Millwood) 2005;24:1290-1295.

2. Tang PC, Ash JS, Bates DW, Overhage JM, Sands DZ. Personal health records: Definitions, benefits, and strategies for overcoming barriers to adoption. J Am Med Inform Assoc 2006;13:121-126.

3. Archer N, Fevrier-Thomas U, Lokker C, McKibbon KA, Straus SE. Personal health records: A scoping review. J Am Med Inform Assoc 2011;18:515-522.

4. Personal health records and personal health record systems: A report and recommendations from the National Committee on Vital and Health Statistics. 2006. Available at www.ncvhs.hhs.gov/0602nhiirpt.pdf (last accessed February 12, 2014).

5. Detmer D, Bloomrosen M, Raymond B, Tang P. Integrated personal health records: transformative tools for consumer-centric care. BMC Med Inform Decis Mak 2008;8:45.

6. Kaelber D, Pan EC. The value of personal health record (PHR) systems. AMIA Annu Symp Proc 2008;343-347.

7. Fricton JR, Davies D. Personal health records to improve health information exchange and patient safety. In: Henriksen $K_{1}$ Battles JB, Keyes MA, et al., eds. Advances in patient safety: New directions and alternative approaches, Vol. 4: Technology and medication safety. Rockville, MD: Agency for Healthcare Research and Quality, 2008. Available at www.ncbi.nlm.nih.gov/books/ NBK43760/ (last accessed February 12, 2014).

8. Reti SR, Feldman HJ, Ross SE, Safran C. Improving personal health records for patient-centered care. J Am Med Inform Assoc 2010;17:192-195.

9. Segall N, Saville JG, L'Engle P, Carlson B, Wright MC, Schulman K, Tcheng JE. Usability evaluation of a personal health record. AMIA Annu Symp Proc $2011 ; 1233-1242$.

10. Woods SS, Schwartz E, Tuepker A, Press NA, Nazi KM, Turvey CL, Nichol WP. Patient experiences with full electronic access to health records and clinical notes through the My HealtheVet personal health record pilot: Qualitative study. J Med Internet Res 2013;15:e65.

11. Young-Mason J. Information and knowledge is power: The online personal health record. Clin Nurse Spec 2013;27:105-106.

12. Boulos MN, Wheeler $S$, Tavares $C$, Jones R. How smartphones are changing the face of mobile and participatory healthcare: An overview, with example from eCAALYX. Biomed Eng Online 2011;10:24.

13. Ozdalga $E$, Ozdalga $A$, Ahuja N. The smartphone in medicine: A review of current and potential use among physicians and students. J Med Internet Res 2012;14:e128.

14. Allaert FA, Quantin C. Patients' empowerment of their personal health record requires strong traceability to guarantee patients health care security. Stud Health Technol Inform 2010;155:43-47.

15. Lee JH. Smart health: Concepts and status of ubiquitous health with smartphone. 2011 International Conference on ICT Convergence (ICTC). New York: IEEE, 2011;388-389. 
16. Ricciardi L, Mostashari F, Murphy J, Daniel JG, Siminerio EP. A national action plan to support consumer engagement via e-health. Health Aff (Millwood) 2013;32:376-384.

17. Krist $A H$, Peele $E$, Woolf $S H$, Rothemich SF, Loomis JF, Longo DR, Kuzel AJ. Designing a patient-centered personal health record to promote preventive care. BMC Med Inform Decis Mak 2011;11:73.

18. Yamin CK, Emani S, Williams DH, Lipsitz SR, Karson AS, Wald JS, Bates DW. The digital divide in adoption and use of a personal health record. Arch Intern Med 2011;171:568-574.

19. Park JY, Lee G, Shin SY, Kim JH, Han HW, Kwon TW, Kim WS, Lee JH. Lessons learned from the development of health applications in a tertiary hospital. Telemed J E Health 2014;20:215-222.

20. Nazi KM. Veterans' voices: Use of the American Customer Satisfaction Index (ACSI) Survey to identify My HealtheVet personal health record users' characteristics, needs, and preferences. J Am Med Inform Assoc 2010;17: 203-211.

21. Detmer $D$, Bloomrosen $M$, Raymond B, Tang P. Integrated personal health records: Transformative tools for consumer-centric care. BMC Med Inform Decis Mak 2008;8:36.

22. Henriksen K, Battles JB, Keyes MA, et al., eds. Advances in patient safety: New directions and alternative approaches, Vol. 3: Performance and tools. Rockville, MD: Agency for Healthcare Research and Quality, 2008. Available at www.ncbi.nlm.nih.gov/books/NBK43665/ (last accessed February 12, 2014).

23. Kim HR. The relationship of socioeconomic position and health behaviors with morbidity in Seoul, Korea. Korea Inst Health Soc Aff 2005;25:3-35.

24. Korea Centers for Disease Control \& Prevention. 2005 health behavior and chronic disease statistics. Available at www.cdc.go.kr/CDC/notice/CdcKrlnfo0201.jsp? menulds=HOME001-MNU1154-MNU0004-MNU0025\&cid=1236 (last accessed February 12, 2014)

25. Dobkin BH, Dorsch $A$. The promise of $m$-Health: Daily activity monitoring and outcome assessments by wearable sensors. Neurorehabil Neural Repair $2011 ; 25: 788-798$

26. Kirwan M, Duncan MJ, Vandelanotte C, Mummery WK. Using smartphone technology to monitor physical activity in the 10,000 Steps program: A matched case-control trial. J Med Internet Res 2012;14:e55.

27. Kharrazi H, Chisholm R, VanNasdale D, Thompson B. Mobile personal health records: An evaluation of features and functionality. Int J Med Inform 2012;81:579-593.

28. Miller $H$, Vandenbosch $B$, Ivanov D, Black P. Determinants of personal health record use: A large population study at Cleveland Clinic. J Healthc Inf Manag 2007;21:44-48.

29. Arsand E, Froisland DH, Skrovseth SO, Chomutare T, Tatara N, Hartvigsen G, Tufano JT. Mobile health applications to assist patients with diabetes: Lessons learned and design implications. J Diabetes Sci Technol 2012;6:1197-1206.
30. Silvestre AL, Sue VM, Allen JY. If you build it, will they come? The Kaiser Permanente model of online health care. Health Aff (Millwood) 2009;28:334-344.

31. Halamka JD, MandI KD, Tang PC. Early experiences with personal health records. J Am Med Inform Assoc 2008;15:1-7.

32. Weingart SN, Rind D, Tofias Z, Sands DZ. Who uses the patient Internet portal? The PatientSite experience. J Am Med Inform Assoc 2006;13:91-95.

33. Kim EH, Stolyar A, Lober WB, Herbaugh AL, Shinstrom SE, Zierler BK, Soh CB, Kim Y. Usage patterns of a personal health record by elderly and disabled users. AMIA Annu Symp Proc 2007;409-413.

34. Emont S. Measuring the impact of patient portals: What the literature tells us. Oakland, CA: California Healthcare Foundation, 2011.

35. Agarwal R, Anderson C, Zarate J, Ward C. If we offer it, will they accept? Factors affecting patient use intentions of personal health records and secure messaging. J Med Internet Res 2013;15:e43.

36. Tenforde $M$, Nowacki $A$, Jain A, Hickner J. The association between personal health record use and diabetes quality measures. J Gen Intern Med 2012;27:420-424.

37. Hassol A, Walker JM, Kidder D, Rokita K, Young D, Pierdon S, Deitz D, Kuck S, Ortiz E. Patient experiences and attitudes about access to a patient electronic health care record and linked web messaging. J Am Med Inform Assoc 2004;11:505-513.

38. Venkatesh V, Morris MG, Davis GB, Davis FD. User acceptance of information technology: Toward a unified view. MIS 0 2003;27:425-478.

39. McCray AT. Promoting health literacy. J Am Med Inform Assoc 2005;12: 152-163.

40. Lober WB, Zierler B, Herbaugh A, Shinstrom SE, Stolyar A, Kim EH, Kim Y. Barriers to the use of a personal health record by an elderly population. AMIA Annu Symp Proc 2006;514-518.

Address correspondence to: Jae Ho Lee, $M D, P h D$ Department of Emergency Medicine University of Ulsan College of Medicine Seoul 138-736 Korea

E-mail: jaeholee@amc.seoul.kr

Received: July 15, 2015

Revised: August 24, 2015 Accepted: August 26, 2015 